\title{
The potentials and challenges of algae based biofuels: A review of the techno-economic, life cycle, and resource assessment modeling
}

\author{
Jason C. Quinn ${ }^{a^{*}}$, Ryan Davis ${ }^{b}$ \\ ${ }^{\mathrm{a}}$ Mechanical and Aerospace Engineering, Utah State University, Logan, Utah, USA, 84341 \\ ${ }^{\text {b}}$ National Renewable Energy Laboratory, Golden Colorado, USA \\ *Author for Correspondence: 430 Old Main Hill, Logan, UT 84322, Phone: 435-797-0341, Fax: 435-797- \\ 2417 Email: Jason.Quinn@usu.edu
}

\begin{abstract}
Microalgae biofuel production has been extensively evaluated through resource, economic and life cycle assessments. Resource assessments consistently identify land as nonlimiting and highlight the need to consider siting based on combined geographical constraints of land and other critical resources such as water and carbon dioxide. Economic assessments report a selling cost of fuel that ranges between $\$ 1$ to over $\$ 30$ gal $^{-1}$ consistent with large variability reported in the life cycle literature, -75 to $534 \mathrm{~g} \mathrm{CO}_{2-\mathrm{eq}} \mathrm{MJ}^{-1}$. Large drivers behind such variability stem from differences in productivity assumptions, pathway technologies, and system boundaries. Productivity represents foundational units in these assessments with current assumed yields in various assessments varying by a factor of 60 . A review of the literature in these areas highlights the need for harmonized assessments such that direct comparisons of alternative processing technologies can be made on the metrics of resource requirements, economic feasibility, and environmental impact.
\end{abstract}

\footnotetext{
${ }^{*}$ Author For Correspondence 


\section{Keywords:}

Life cycle assessment, Techno-economic assessment, Microalgae, Biofuels, Productivity potential

\section{Introduction}

The current increase in global energy demand, as well as the negative impact petroleum based energy sources are having on the environment, has led to a renewed interest in renewable energy resources. A variety of third generation feedstocks for biofuel production are being investigated as viable alternatives to traditional energy sources including microalgae. Microalgae represents a promising alternative based on inherent advantages such as characteristically high lipid yields, potential utilization of poor quality land and water, and integration with point source carbon dioxide sources such as coal fired power plants. Efforts to advance the commercial feasibility of microalgae derived biofuels have focused on improvements to the various processing steps associated with the production of feedstock through to fuel conversion. Resource assessment, techno-economic assessment (TEA), and life cycle assessment (LCA) have been used as foundational tools in evaluating the feasibility of microalgae biofuels. These tool sets have been leveraged to evaluate alternative processing technologies and identify promising production pathways while focusing research and development efforts on the most critical drivers for achieving commercial viability. Multiple production pathways have been identified and modeled but inconsistency in modeling boundaries and processing assumptions have led to a large uncertainty in the current scalability results, leading to a large uncertainty in the current state and future potential of algal based biofuels. 
Significant investments have been made in microalgae as a biofuel feedstock in light of recent renewed interest spurred by uncertainty in energy prices and the promising impact microalgae could have compared to traditional terrestrial crops. The productivity potential of microalgae is a key driver for the investigation of it as a biofuel feedstock. Compared to traditional terrestrial feedstocks, microalgae have the potential to produce at levels that are orders of magnitude higher (Chisti, 2007; Wijffels \& Barbosa, 2010). Achieving this potential has proven difficult at large-scale due to complications associated with culture stability (Quinn et al., 2012c). A large majority of the assessments being conducted are extrapolating laboratory-scale data, conducted under highly-controlled settings and/or short timeframes, which is not representative of large-scale function. Over estimation of yield directly impacts the results of the assessment as yield is typically the functional unit. Advancements in biological growth models are moving toward dynamic modeling to accurately capture biological function and seasonal and geographical variability. Validation of large-scale growth models represents a resource intensive task. However, utilization of dynamic growth models represents an opportunity to dramatically improve the assessment of the microalgae to biofuels process as seasonal and geographic variability can be captured.

Resource assessment has been used to understand the potential limitations to the scalability of microalgae biofuels. Assessments have advanced from simple mass balance calculations to geographically specific assessments incorporating geographical information systems (GIS) data for land, water, and carbon dioxide availability (Pate et al., 2011; Quinn et al., 2012b; Venteris et al., 2014a). Differences in foundational assumptions in regard to productivity and resource availability make directly comparing results challenging. Resource 
assessment and techno-economics have become interconnected in current resource assessments as there are economic limitations to resource delivery and plant sizing. For example, drivers identified by techno-economics directly impact the foundational assumptions associated with land slope tolerance or carbon dioxide transport distances used as screening criteria in a resource assessment models. Uncertainty in techno-economics leads to uncertainty in the tolerance to land slope and carbon dioxide transport. These tradeoffs highlight the need for integration of sustainability models.

TEA modeling has been used to understand the commercial viability of microalgae as a feedstock for biofuel. The immaturity of processing technologies has dramatically impacted the fidelity of foundational sub-process modeling which serves as the backbone for economic assessment. Current TEA results reported in the literature range from being cheaper than conventional diesel by a factor of 3 to an order of magnitude higher (Benemann \& Oswald, 1996; Richardson et al., 2012). A major contributor to differences in results stems from uncertainty in the large-scale productivity of microalgae as this serves as the functional unit of the assessments and production pathway assumptions. Further foundational differences in financial assumptions as well as differences in the level of technical and engineering rigor contribute to the variability in end results.

The environmental impact associated with microalgae biofuels suffers from similar problems as the TEA literature. Current greenhouse gas (GHG) results range from net negative to greater than $500 \mathrm{~g} \mathrm{CO}_{2-\mathrm{eq}} \mathrm{MJ}^{-1}$. Life cycle modeling has been extensively performed with minimal consensus on the current state of microalgae biofuels. Direct comparisons of studies are difficult based on differences in system boundaries and core LCA assumptions. Varying 
assumptions in regard to co-product allocation methods, electrical energy sourcing, and life cycle inventory data dramatically impact results. Further differences in processing pathways and unrealistic validation of sub-processing models with small-scale data contribute to the large variability in reported results.

Differences in system boundaries, processing pathways, and life cycle and economic assumptions make direct comparisons of current sustainability assessments challenging.

Resource assessment, TEA, and LCA are typically performed independently further complicating comparisons between alternative production pathways and emerging technologies on resource demand, economic feasibility and environmental impact. When conducted independently, these types of models carry a high probability that the results will not allow for interpreting implications consistently (for example, dollar-per-gallon fuel costs from one model and GHG emissions from another). As such there is a need to integrate modeling efforts and realize transparent results such that direct comparison of sub-process technologies can be understood on a systems level. Consistent system boundaries that facilitate the comparison of processing technologies can facilitate a better understanding of the impact and limitations of biofuels derived from microalgae on the metrics of economic feasibility, environmental impact, and resource demand. This paper reviews the current progress in resource modeling, TEA, and LCA literature highlighting the need for harmonized modeling efforts based on well-informed, rigorous, engineering-based process models.

\section{Growth Modeling}

Growth modeling represents a critical component to scalability assessments as results are typically reported based on oil yield. Large differences in productivity potential 
assumptions in the various studies have directly contributed to the large variance in reported results. There is a current need to better understand the near-term realizable biomass productivity potential and associated composition. Advancements in growth modeling have shown microalgae productivity cannot be linearly scaled from laboratory data and assumed to be fixed day to day (Davis et al., 2014b; Moody et al., 2014).

The high productivity potential associated with microalgae is one of the primary drivers for interest in exploring it as a feedstock for biofuel production. Various theoretical studies have been performed to understand the upper limit of microalgae productivity based on thermodynamic limitations (Weyer et al., 2009; Zemke et al., 2010). Directly comparing Zemke et al. (2010) and Weyer et al. (2009) requires harmonization due to foundational differences in assumed solar radiation. Zemke et al. (2010) report a yield of $240 \mathrm{~m}^{3} \mathrm{ha}^{-1} \mathrm{yr}^{-1}$ based on a facility located in the southwestern US while Weyer et al. (2009) report $350 \mathrm{~m}^{3} \mathrm{ha}^{-1} \mathrm{yr}^{-1}$ based on a facility located at the equator in an effort to evaluate an upper limit on productivity as the equator would have the highest annual solar irradiance. Harmonization of the two studies shows a similar maximum theoretical yield of approximately $350 \mathrm{~m}^{3} \mathrm{ha}^{-1} \mathrm{yr}^{-1}\left(37,000\right.$ gal acre $^{-1}$ $\mathrm{yr}^{-1}$ ) when the facility is located at the equator representing an optimum location based on solar radiation. Backing down from this maximum thermodynamic theoretical limit, Weyer et al. (2009) report a realistic best case practical yield of $40 \mathrm{~m}^{3} \mathrm{ha}^{-1} \mathrm{yr}^{-1}\left(4,000\right.$ gal acre $\left.^{-1} \mathrm{yr}^{-1}\right)$. It should be noted that these yield values are all based on conversion technologies focused exclusively on the lipid fraction of the biomass (e.g. lipid extraction), and focus has recently shifted towards higher-yielding conversion pathways based either on conversion of whole algal biomass or of multiple biomass constituents. 
Productivity potential represents a key constituent in modeling efforts as yield defines

the functional unit. The current near-term productivity potential for microalgae at large-scale is typically being estimated through linear extrapolation from laboratory based growth and lipid data which has led to a large variance in reported values (Moody et al., 2014). This type of scaling has been integrated into many engineering system models that represent the backbone of various resource assessments, TEAs, and LCAs of the microalgae to biofuels process. This type of growth modeling leads to unrealistic assumptions about industrial function and represents a source of large uncertainty in the modeling of commercial-scale, year-round production systems. Current near-term algal lipid productivity values reported in resource assessment, TEA, and LCA literature range from $2.3 \mathrm{~m}^{3} \mathrm{ha}^{-1} \mathrm{yr}^{-1}\left(245\right.$ gal acre $\left.^{-1} \mathrm{yr}^{-1}\right)$ reported by Ramachandra et al. (2013) to $136.9 \mathrm{~m}^{3} \mathrm{ha}^{-1} \mathrm{yr}^{-1}\left(14,636\right.$ gal acre $\left.\mathrm{yr}^{-1}\right)$ reported by Mata et al. (2010) with a variety of researchers reporting values between these two extremes (Amer et al., 2011; ANL et al., June 2012; Azadi et al., 2014; Batan et al., 2010; Benemann et al., 1982; Benemann \& Oswald, 1996; Brentner et al., 2011; Campbell et al., 2011; Chisti, 2007; Chisti, 2008a; Chisti, 2008b; Clarens et al., 2010; Davis et al., 2011; Frank et al., 2013; Guieysse et al., 2013; Lam \& Lee, 2012; Lardon et al., 2009; Liu et al., 2013; Mata et al., 2010; Moheimani, 2013; Nagarajan et al., 2013; Passell et al., 2013; Pate, 2013; Pienkos \& Darzins, 2009; Quinn et al., 2012c; Ramachandra et al., 2013; Rodolfi et al., 2009; Rogers et al., 2014; Schenk et al., 2008; Scott et al., 2010; Shirvani et al., 2011; Soratana \& Landis, 2011; Sun et al., 2011; Vasudevan et al., 2012; Wijffels \& Barbosa, 2010; Williams \& Laurens, 2010; Xu et al., 2011; Yeang, 2008), Figure 1. 
The high values reported in the literature survey are typically the result of speculation as to future attainable productivity potential based on the linear scaling of laboratory growth data (Chisti, 2007; Mata et al., 2010). The high value reported by Mata et al. (2010) is $40 \%$ of the theoretical maximum determined by Weyer et al. (2009). The low values reported represent productivities currently observed in outdoor systems (Lam \& Lee, 2012; Ramachandra et al., 2013). Large uncertainty not only across the literature but in individual articles is also illustrated in Figure 1. Passell et al. (2013) perform a LCA based on commercial data represented with a productivity of $3.1 \mathrm{~m}^{3} \mathrm{ha}^{-1} \mathrm{yr}^{-1}$, and increase the productivity to $53 \mathrm{~m}^{3} \mathrm{ha}^{-1} \mathrm{yr}^{-}$ ${ }^{1}$ for a future case assessment representing a 17 fold increase. Pienkos and Darzins (2009) report low (conservative) and high (optimistic) production scenarios that differ by a factor of 16. The large variability across the literature and within studies illustrates the uncertainty in both current and future potential microalgae productivity.

Selective studies have made progress in developing dynamic productivity models. Biomass productivity studies for two different production systems based on experimentally validated biological models have been integrated with historical meteorological data for geographically and seasonally resolved assessments of microalgae productivity, presented in Davis et al. (2014b) for open raceway ponds (ORP) and Quinn et al. (2012a) for photobioreactors (PBR). ANL; NREL; PNNL (June 2012) which feeds into the work of Davis et al. (2014b) report an annual average productivity of $13 \mathrm{~g} \mathrm{~m}^{-2} \mathrm{~d}^{-1}$ while Quinn et al. report $10 \mathrm{~g} \mathrm{~m}^{-2}$ $d^{-1}$. Both modeling efforts include temperature effects as large-scale production facilities will not have active thermal regulation. Differences in reported productivity are attributed to foundational differences in modeling approach and production systems. Growth modeling 
work by Davis et al. (2014b) is based on a biophysics growth model that uses experimentally determined parameters for promising species to characterize growth and approximate yield with the productivity at various US locations based on integration of results with climatic data. Quinn et al. (2012a) use a biological model that incorporates a dynamic lipid model both founded on literature and then validated through pilot plant growth data as detailed in Quinn et al. (2012c) with historical meteorological data to understand the current near-term productivity potential in the US. Work was extended from a national assessment to a global assessment of productivity potential by Moody et al. (2014). Results presented in Moody et al. (2014) include average biomass and lipid productivities and seasonal variability for 56 different countries based on simulation of 4,388 different locations.

Large-scale model validation has proven challenging based on limited publication of productivity data. Solix BioSystems has published production data from pilot plant PBR operation in 2009 and 2010 cultivating Nannochloropsis oculata and salina. Results show a large seasonal variability with peak summer growth rates of $18.3 \mathrm{~g} \mathrm{~m}^{-2} \mathrm{~d}^{-1}$ and annual average growth rate of $8.0 \mathrm{~g} \mathrm{~m}^{-2} \mathrm{~d}^{-1}$ for $N$. salina. Similar data sets for other growth platforms and strains would support the validation of growth assumptions and decrease the current uncertainty in microalgae productivity potential. While such data has proven scarce in the public domain to date, new multi-organization consortia groups are also working to generate data for outdoor cultivation over all seasons of the year and across multiple locations in the U.S. (Arizona State University, 2014).

Growth modeling directly impacts resource assessments, TEAs, and LCAs as yield is typically the functional unit and critically impacts results. Current uncertainty in productivity 
potential, both in absolute terms on an annual average as well as on a seasonal basis, has led to unrealistic extrapolation of laboratory based data. Davis et al. (2014b) and the harmonization effort by ANL; NREL; PNNL (June 2012) are the only studies identified that evaluate the impact of seasonal variability in productivity on assessing microalgae based biofuels. Moody et al.

(2014) report seasonal variability in productivity in the global modeling work that was performed that can be leveraged for future assessments. Dynamic seasonal modeling has been shown to be an important next step in scalability assessments.

\section{Microalgae Scalability based on Resource Assessment}

Various efforts have been made to understand the resource requirements associated with microalgae biofuel production systems and the corresponding scalability (ANL; NREL; PNNL, June 2012; Batan et al., 2013; Davis et al., 2014b; Fortier \& Sturm, 2012; Moody et al., 2014; Pate et al., 2011; Quinn et al., 2012a; Quinn et al., 2012b; Venteris et al., 2014a; Venteris et al., 2012; Venteris et al., 2013; Venteris et al., 2014b; Wigmosta et al., 2011). Results from these studies have evaluated land, carbon dioxide, water, and nutrient requirements for biofuel production from microalgae and directly compared requirements to current available resources. Large uncertainty in results stem from different assumptions in regard to productivity and scope of the study.

Critical resources for large-scale production include nitrogen and phosphorous. Large uncertainty in the requirements of these resources for scaled production stems from differences in process integration strategies. A production pathway that includes an anaerobic digestion step for residual biomass will dramatically decrease the raw nitrogen and phosphorus requirements for cultivation through nutrient recycling compared to a pathway that does not 
allow for capture and reuse of these components. First order modeling of nitrogen and phosphorous requirements by Pate et al. (2011) show these nutrients could represent a potential limiting resource for scaling algal systems to nationally relevant scales. Some select LCAs and TEAs have identified the need for recycling of nutrients but have not performed the a rigorous assessment of the large-scale impact (Batan et al., 2010).

Water requirements are growth system specific and the corresponding requirements will differ drastically for ORP compared to a tubular or flat plate PBR. Further, water requirements for cultivation are shown to be geographically dependent. Average water requirements reported by Pate et al. (2011), Wigmosta et al. (2011), and Batan et al. (2013), are 607,1000 , and 1944 I-water I-oil $^{-1}$, respectively. The large variability is due to differences in growth architectures, assumed productivities, and geographical location. Compared to traditional feedstocks microalgae are shown to be water intensive (Wigmosta et al., 2011). Nutrients and water represent important resource considerations, however there has been limited work in the area compared to land and carbon dioxide.

\subsection{Land Requirements}

Microalgae have the inherent advantage of not competing with traditional terrestrial crops for valuable agricultural land and thus do not directly compete with food. Various studies have investigated the potential scalability limitations of land as a resource. Results from Pate et al. (2011), Wigmosta et al. (2011), and Quinn et al. (2012a) all independently investigate land requirements for large-scale microalgae production in the US. Pate et al. (2011) perform a first order mass balance calculation based on a fixed productivity for various production levels and geographic locations with land availability limited to pasture land. Wigmosta et al. (2011), and 
Quinn et al. (2012a) integrate geographically resolved historical meteorological data with dynamic growth models and GIS land calcification and slope data to evaluate the productivity potential in the US. Differences in core growth modeling and land classification limit a direct comparison of the geographically realized studies. The annual average productivity modeled in Pate et al. (2011), Wigmosta et al. (2011), and Quinn et al. (2012a) was 19.6, 4.64, and $18 \mathrm{~m}^{3}$ $\mathrm{ha}^{-1} \mathrm{yr}^{-1}$, respectively. Productivity differences are the results of differences in growth modeling. Pate et al. (2011) assumes a fixed productivity between 19 and $60 \mathrm{~m}^{3} \mathrm{ha}^{-1} \mathrm{yr}^{-1}$ depending on region. Wigmosta et al. (2011) use a growth model that is based on a photosynthetic efficiency and fixed lipid content while Quinn et al. (2012a) use an experimentally validated biological growth model. Differences in land availability and geographic restriction assumptions result in differences in land availability results, 19, 43, and 75 million hectares reported by Pate et al. (2011), Wigmosta et al. (2011), and Quinn et al. (2012a), respectively. Harmonizing the three studies to evaluate the productivity potential based on similar assumptions in regard to productivity, $18 \mathrm{~m}^{3} \mathrm{ha}^{-1} \mathrm{yr}^{-1}$, and land availability, 75 million hectares, the biofuel production results translate to $1.47,1.48$, and 1.59 billion $\mathrm{m}^{3} \mathrm{yr}^{-1}$ for Pate et al. (2011), Wigmosta et al. (2011), and Quinn et al. (2012a), respectively. All three studies have similar results when harmonized and are at a level that is an order of magnitude higher than the current 2030 DOE renewable fuel goal, replacement of $30 \%$ of transportation fuel or approximately 0.160 billion $\mathrm{m}^{3} \mathrm{yr}^{-1}$. The three harmonized studies show land is not expected to represent a scalability issue for microalgae based biofuels. 


\subsection{Carbon Dioxide Requirements}

Carbon dioxide represents an important nutrient for accelerated growth in aqueous based microalgae cultivation, which is critical for economic viability of a commodity product such as biofuel. Challenges associated with the economical delivery and utilization of gaseous carbon dioxide has typically been ignored in TEA and LCA studies. A large number of TEAs and LCAs assume the co-location of production facilities with industrial waste carbon dioxide without considering the scalability implications. Pate et al. (2011) perform a first order assessment on carbon dioxide availability. Given a yield estimate of $19 \mathrm{~m}^{3} \mathrm{ha}^{-1} \mathrm{yr}^{-1}$, results show for 19 lower-tier states (AZ, AK, AL, CA, CO, FL, GA, IA, KS, LA, MO, MS, NE, NM, NV, OK, SC, TX and UT) approximately 20 billion gallons of fuel can be produced annually without night storage, based on point-source carbon dioxide availability constraints. Quinn et al. (2012b) integrate GIS land restrictions of barren land with less than $2 \%$ slope and carbon dioxide availability data and results from a biological growth model used to estimate productivity potential and economic constraints on carbon dioxide transport to better understand production capacity. Results show a modeled US average productivity of $19 \mathrm{~m}^{3} \mathrm{ha}^{-1} \mathrm{yr}^{-1}$ and a carbon dioxide transport distance limitation of $4.8 \mathrm{~km}$ corresponding to a production of 1.9 billion gallons of fuel annually. Venteris et al. (2014b) combine various resources including land, water, and carbon dioxide to investigate feasible siting locations to minimize resource costs. Results from this work show 21 billion gallons can be achieved utilizing $20 \%$ of the US waste carbon dioxide annually. Results associated with the transportation limits on carbon dioxide are not explicitly presented in Venteris et al. (2014b) as costs for land, water and carbon dioxide delivery are lumped together. Quinn et al. (2012b) and Venteris et al. (2014b) both 
highlight the need to understand the costs associated with the delivery of carbon dioxide with Quinn et al. (2012b) identifying land and carbon dioxide as a scalability barrier. None of the studies identified have investigated the impact of power plant load on carbon dioxide availability or the potential negative impacts associated with flue gas contaminants on algal growth. Carbon dioxide represents an important nutrient for which many studies underestimate the cost of delivery. Sighting of microalgae cultivation facilities can be limited based on the availability and costs associated with this resource when combined with land resource limitations.

\section{Techno-economic Feasibility}

TEA has emerged as a key assessment tool in understanding cost benchmarks for today's state of algal technologies, as well as the potential feasibility and required research and development areas for algal biofuel processes moving forward. TEA couples engineering-based process modeling (typically conducted in process simulation software packages) with economic estimates and financial assessment to quantify product selling prices, typically on a dollar-pergallon basis. Rigorous TEA requires a sound technical understanding of the process, to first establish mass and energy balance estimates on a process-unit-level basis, as an important precedent to developing associated unit operation capital and operating cost estimates that can seamlessly be integrated into a production pathway assessment.

A number of TEAs have been completed to analyze the economic feasibility of various biofuel pathways based on a microalgae feedstock (Amer et al., 2011; ANL; NREL; PNNL, June 2012; Benemann et al., 1982; Benemann \& Oswald, 1996; Chisti, 2007; Davis et al., 2011; Davis et al., 2014b; Jones et al., 2014; Lundquist et al., 2010; Nagarajan et al., 2013; Pienkos \& 
Darzins, 2009; Richardson et al., 2012; Rogers et al., 2014; Sun et al., 2011; Thilakaratne et al., 2014; Williams \& Laurens, 2010). The results of the studies surveyed have a large variability in the calculated fuel cost, Figure 2. For comparison of studies, results have all been converted to 2014 dollars based on an inflation rate of $2.4 \%$. A low cost for production of $\$ 1.65 \mathrm{gal}^{-1}$ is reported by Bennemann and Oswald (1996) with a high cost of $\$ 33.16 \mathrm{gal}^{-1}$ reported by Richardson et al. (2012). Differences between reported results can be attributed to differences in boundaries, processing pathways, and modeling of either current or future systems. Differences in production pathway and system boundaries have resulted in a meta-analyses completed by Sun et al. (2011) to harmonize the modeling efforts of four studies with published results that originally ranged from $\$ 11.40 \mathrm{gal}^{-1}$ to $\$ 27.10 \mathrm{gal}^{-1}$. The meta-analysis resulted in much closer agreement, with a harmonized range of $\$ 11.68 \mathrm{gal}^{-1}$ to $\$ 14.31 \mathrm{gal}^{-1}$ illustrating the significant reduction in variability through utilizing similar growth and production pathway assumptions (values reported here are 2014 dollars). Variability is not limited to the surveyed literature but is also found within individual studies. Peinkos and Darzins (2009) report cost differences by an order of magnitude primarily due to large variability in the assumed productivity projections.

Significant cost differences are also shown between the competing growth architectures, ORP and PBR. All of the studies that directly compare the costs associated with ORP to PBR conclude ORP are economically advantageous by more than a factor of 2 (Davis et al., 2011; Richardson et al., 2012). The economic studies of PBR currently assume similar productivities and culture stability as modeled in ORP systems. This type of growth modeling 
does not accurately capture the expected function of a large-scale PBR system as improved productivity and culture stability are expected compared to open systems (Quinn et al., 2012c).

The economic estimates associated with the production of fuel from microalgae reported in the literature ranges by a factor of 20. Foundationally, some TEAs are focused on a current assessment while others are aimed at modeling futuristic aspirational scenarios which contributes to some of the variability in costs reported here. Additionally, financial assumptions can play large roles in influencing TEA results, including parameters such as facility lifetime, on-stream operating factor, discount rate, depreciation method, financing assumptions, and other financial hurdle metrics. From a process standpoint, productivity represents a primary input to TEA modeling as it is the functional unit that costs are reported on. The lipid productivity reported by the studies surveyed range by a factor of 20 from 6.4 to $127 \mathrm{~m}^{3} \mathrm{ha}^{-1} \mathrm{yr}^{-1}$ (684 to $13,500 \mathrm{gal} \mathrm{acre}^{-1} \mathrm{yr}^{-1}$ ). A comparison of recent (post 2007) results for biofuel costs and lipid productivity are presented in Figure 3. Thermochemical conversion studies, hydrothermal liquefaction (HTL) and pyrolysis, have been excluded as a lipid percentage is not reported, thus these values are all based on a lipid-extraction technology focus. As expected the economic viability of microalgae biofuel systems is positively and drastically impacted by increased lipid productivity. Studies that stipulate a lipid productivity of greater than $37 \mathrm{~m}^{3} \mathrm{ha}^{-1} \mathrm{yr}^{-1}$ are shown to suggest results that begin reaching cost competitiveness with traditional fuels. A similar power regression trend in cost with lipid productivity is shown for both growth architectures illustrating the importance of growth modeling in TEAs. 
While on a high level lipid productivity on an annual basis is convenient for understanding trends and cost drivers, the analysis becomes more complex when additional rigor is introduced to consider the impact of seasonal variability within a year. As an aquatic system with very high (>99 wt\%) moisture content at harvest, the harvested material must be processed immediately or dried for later use; given growth model results which indicate a strong seasonality effect which translates to as much as a 5- or 10:1 variation in biomass productivity between peak (summer) and minimum (winter) seasons, this introduces additional implications on how facility processing equipment must be designed to accommodate capital over-design or alternative storage scenarios. This can introduce important differences in both TEA and LCA results, as documented in ANL; NREL; PNNL (June 2012), Davis et al. (2014a), Jones et al. (2014), and Davis et al. (2014b).

TEA represents a powerful tool that can be used to better understand the current commercial viability of microalgae biofuel systems. Currently, a large variability exists in results primarily attributed to differences in growth architecture, production pathways, financial inputs, and productivity assumptions.

\section{Environmental Impact}

LCA facilitates a holistic comparison of individual sub-processes as the work requires considering the production system from growth to fuel. LCA has become a premier tool in assessing process energetics and environmental impacts of biofuels production systems. The current immaturity of the microalgae to biofuels process has led to the evaluation of a variety of processing technologies on the metrics of global warming potential and net energy ratio (NER) or energy return on investment (EROI). Multiple LCAs of microalgae to biofuels processes 
incorporating various conversion technologies have been performed with results varying dramatically due to simplistic process models, differences in production pathways, and incomplete system boundaries (Adesanya et al., 2014; Azadi et al., 2014; Batan et al., 2010; Brentner et al., 2011; Campbell et al., 2011; Collet et al., 2014; Frank et al., 2013; Frank et al., 2011; Grierson et al., 2013; Handler et al., 2014; Liu et al., 2013; Passell et al., 2013; Ponnusamy et al., 2014; Quinn et al., 2014; Shirvani et al., 2011; Sills et al., 2013; Soh et al., 2014;

Vasudevan et al., 2012; Woertz et al., 2014). The majority of the previous studies have focused on traditional lipid extraction systems (Adesanya et al., 2014; Azadi et al., 2014; Batan et al., 2010; Brentner et al., 2011; Campbell et al., 2011; Collet et al., 2014; Frank et al., 2011; Handler et al., 2014; Passell et al., 2013; Quinn et al., 2014; Shirvani et al., 2011; Sills et al., 2013; Soh et al., 2014; Vasudevan et al., 2012; Woertz et al., 2014). Other LCA studies surveyed utilized thermochemical conversion, secretion or supercritical water bio-oil recovery technologies (Brentner et al., 2011; Frank et al., 2013; Grierson et al., 2013; Handler et al., 2014; Liu et al., 2013; Ponnusamy et al., 2014; Vasudevan et al., 2012). The LCAs surveyed here are limited to studies that perform an assessment with a well to pump system boundary and report GHG emissions, Figure 4. For studies that report results with a system boundary of well to wheel or

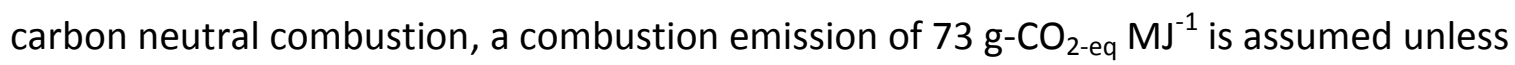
otherwise stated in the study such that results are all compared on a well to pump boundary. A variety of other studies perform LCAs on the metrics of NER or EROI and are not included here (Menger-Krug et al., 2012; Razon \& Tan, 2011; Sevigné Itoiz et al., 2012; Slade \& Bauen, 2013; Soratana \& Landis, 2011). 
Thermochemical conversion, specifically HTL, represents a promising technology based on the ability to convert a wet feedstock to bio-oil. Assessment of the production of fuel via HTL on the metrics of net energy and GHG emissions has been limited (De Boer et al., 2012; Frank et al., 2013; Grierson et al., 2013; Liu et al., 2013). Frank et al. (2013) examined the environmental impact of an HTL process with a well to pump (WTP) system boundary, and includes an additional processing of HTL byproducts to biogas. de Boer et al. (2012) evaluates HTL as a conversion system but fails to include microalgae growth, downstream processing of bio-oil, and HTL byproducts in the analysis. The results from the literature survey show a best case WTP GHG emissions for a processes utilizing HTL for conversion of -44 $\mathrm{g} \mathrm{CO}_{2 \text {-eq }} \mathrm{MJ}^{-1}$ reported by Frank et al. (2013) compared to the best case scenario of -95.7 reported by Ponnusamy et al. (2014) which utilizes a super critical water technology for lipid recovery. One other study, Liu et al. (2013), examined conversion through HTL, with GHG emission reported at $33 \mathrm{~g} \mathrm{CO}_{2-e q} \mathrm{MJ}^{-1}$. Differences in results from the various studies stem from process pathways and assumed HTL performance. An alternative thermochemical conversion process, pyrolysis has also been explored. Current results show it does not represent an environmentally favorable conversion technology due to drying requirements (Grierson et al., 2013). The majority of the LCAs surveyed utilize a solvent extraction for recovering of lipids. This produces lipid extracted algae that is then typically utilized as a feedstock to an anaerobic digester. Anaerobic digestion is advantageous as it produces methane which can be combusted on-sight for heat and power generation and the nutrient rich effluent can be recycled in the growth system. The pre-processing requirements required for minimizing negative effects of integrating anaerobic digestion effluent on culture stability and productivity has not been fully 
investigated. The LCAs that integrate anaerobic digestion assume a seamless integration. Subprocess models of the anaerobic digestion system have typically over estimated methane yields from the digestion of lipid extracted algae as models have been validated with experimental results of the digestion of whole microalgae (Quinn et al., in press). Anaerobic digestion has been shown to positively impact LCA due to the over estimation of methane yields. This result highlights the need for experimentally validated sub-process models.

The system boundary used for the evaluation of the microalgae to biofuels process typically excludes the emissions associated with the construction of the facility (Adesanya et al., 2014; Canter et al., 2012). Adesanya et al. (2014) performs an assessment that integrates these emissions with the assessment of the production of fuel while Canter et al. (2012) strictly reports the emissions associated with construction. Results show the impact of infrastructure GHG emissions can be significant depending on the yield of the system. Canter et al. report 8.9 $\mathrm{g} \mathrm{CO}_{2 \text {-eq }} \mathrm{MJ}^{-1}$ based on a growth rate of $13 \mathrm{~g} \mathrm{~m}^{-2} \mathrm{~d}^{-1}$ and a plant lifetime of 30 years.

LCA is a powerful tool in evaluating emerging technologies when high fidelity engineering sub-process models are developed and integrated into an engineering system backbone. Lack of validation data or the scaling of laboratory data has negatively impacted assessments. Further, differences in core LCA assumptions such as electrical sourcing, coproduct credits, and system boundary make direct comparisons of alternative production pathways challenging.

\section{Conclusions}

Microalgal-derived biofuels represent a promising alternative to traditional terrestrial crops. Current assessment of the scalability of microalgae biofuels has suffered from the 
extrapolation of laboratory data, inconsistencies in system boundaries, and differences in production pathway architecture. Individual studies have investigated the impacts of subprocessing technologies on the metrics of resource demand, economic feasibility and environmental impact. The large variability in assessments highlights the need for integrated resource assessments, TEA, and LCA constructed on a foundation of experimentally validated engineering system models and use of dynamic growth modeling.

\section{Acknowledgments:}

The authors greatly acknowledge support from Justin Hoffman and Danna Quinn. This work was supported in part by the U.S. Department of Energy, Bioenergy Technologies Office (BETO) under contract number DE-AC36-08-GO28308 to NREL. The National Renewable Energy Laboratory (NREL) is a national laboratory of the U.S. Department of Energy, Office of Energy Efficiency and Renewable Energy, operated by the Alliance for Sustainable Energy, LLC.

\section{References}

Adesanya, V.O., Cadena, E., Scott, S.A., Smith, A.G., 2014. Life cycle assessment on microalgal biodiesel production using a hybrid cultivation system. Bioresour Technol, 163(0), 343-355.

Amer, L., Adhikari, B., Pellegrino, J., 2011. Technoeconomic analysis of five microalgae-to-biofuels processes of varying complexity. Bioresour Technol, 102(20), 9350-9359.

ANL, NREL, PNNL. June 2012. Renewable diesel from algal lipids: An integrated baseline for cost, emissions, and resource potential from a harmonized model. US Department of Energy Biomass Program.

Arizona State University. 2014. Arizona center for algae technology and innovation. http://www.azcati.com/, Accessed:Aug. 2014. 
Azadi, P., Brownbridge, G., Mosbach, S., Smallbone, A., Bhave, A., Inderwildi, O., Kraft, M., 2014. The carbon footprint and non-renewable energy demand of algae-derived biodiesel. Applied Energy, 113(0), 1632-1644.

Batan, L., Quinn, J., Willson, B., Bradley, T., 2010. Net energy and greenhouse gas emission evaluation of biodiesel derived from microalgae. Environ Sci Technol, 44, 7975-7980.

Batan, L., Quinn, J.C., Bradley, T.H., 2013. Analysis of water footprint of a photobioreactor microalgae biofuel production system from blue, green and lifecycle perspectives. Algal Research, 2(3), 196203.

Benemann, J.R., Goebel, R.P., Weissman, J.C., Augenstein, D.C., 1982. Microalgae as a source of liquid fuels. Final Technical Report, US Department of Energy, Office of Research, DOE/ER/30014-TR.

Benemann, J.R., Oswald, W.J. 1996. Systems and economic analysis of microalgae ponds for conversion of $\mathrm{CO}_{2}$ to biomass. Final report. DOE/PC/93204--T5; Other: ON: DE97052880; TRN: TRN: 97:004328.

Brentner, L.B., Eckelman, M.J., Zimmerman, J.B., 2011. Combinatorial life cycle assessment to inform process design of industrial production of algal biodiesel. Environ Sci Technol, 45(16), 70607067.

Campbell, P.K., Beer, T., Batten, D., 2011. Life cycle assessment of biodiesel production from microalgae in ponds. Bioresour Technol, 102(1), 50-56.

Canter, C.E., Davis, R., Urgun-Demirtas, M., Frank, E.D., 2012. Infrastructure associated emissions for renewable diesel production from microalgae. Algal Research, 1(1), 83-92.

Chisti, Y., 2007. Biodiesel from microalgae. Biotechnol Adv, 25(3), 294-306.

Chisti, Y., 2008a. Biodiesel from microalgae beats bioethanol. Trends Biotechnol, 26(3), 126-131.

Chisti, Y., 2008b. Response to reijnders: Do biofuels from microalgae beat biofuels from terrestrial plants? Trends Biotechnol, 26(7), 351-352. 
Clarens, A.F., Resurreccion, E.P., White, M.A., Colosi, L.M., 2010. Environmental life cycle comparison of algae to other bioenergy feedstocks. Environ Sci Technol, 44(5), 1813-1819.

Collet, P., Lardon, L., Hélias, A., Bricout, S., Lombaert-Valot, I., Perrier, B., Lépine, O., Steyer, J.-P., Bernard, O., 2014. Biodiesel from microalgae - life cycle assessment and recommendations for potential improvements. Renewable Energy, 71(0), 525-533.

Davis, R., Aden, A., Pienkos, P.T., 2011. Techno-economic analysis of autotrophic microalgae for fuel production. Applied Energy, 88(10), 3524-3531.

Davis, R., Kinchin, C., Markham, J., Tan, E.C.D., Laurens, L.M.L., 2014a. Process design and economics for the conversion of algal biomass to biofuels: Algal biomass fractionation to lipid- and carbohydrate-derived fuel products. U.S. Department of Energy Bioenergy Technologies Office.

Davis, R.E., Fishman, D.B., Frank, E.D., Johnson, M.C., Jones, S.B., Kinchin, C.M., Skaggs, R.L., Venteris, E.R., Wigmosta, M.S., 2014b. Integrated evaluation of cost, emissions, and resource potential for algal biofuels at the national scale. Environ Sci Technol, 48(10), 6035-6042.

De Boer, K., Moheimani, N., Borowitzka, M., Bahri, P., 2012. Extraction and conversion pathways for microalgae to biodiesel: A review focused on energy consumption. J Appl Phycol, 24(6), 16811698.

Fortier, M.-O.P., Sturm, B.S.M., 2012. Geographic analysis of the feasibility of collocating algal biomass production with wastewater treatment plants. Environ Sci Technol, 46(20), 11426-11434.

Frank, E., Elgowainy, A., Han, J., Wang, Z., 2013. Life cycle comparison of hydrothermal liquefaction and lipid extraction pathways to renewable diesel from algae. Mitigation and Adaptation Strategies for Global Change, 18(1), 137-158.

Frank, E.D., Han, J., Palou-Rivera, I., Elgowainy, A., Wang, M.Q. 2011. Life-cycle analysis of algal lipid fuels with the GREET model. Center for Transportation Research, Energy Systems Division, Argonne National Laboratory. 
Grierson, S., Strezov, V., Bengtsson, J., 2013. Life cycle assessment of a microalgae biomass cultivation, bio-oil extraction and pyrolysis processing regime. Algal Research, 2(3), 299-311.

Guieysse, B., Béchet, Q., Shilton, A., 2013. Variability and uncertainty in water demand and water footprint assessments of fresh algae cultivation based on case studies from five climatic regions. Bioresour Technol, 128(0), 317-323.

Handler, R.M., Shonnard, D.R., Kalnes, T.N., Lupton, F.S., 2014. Life cycle assessment of algal biofuels: Influence of feedstock cultivation systems and conversion platforms. Algal Research, 4(0), 105115.

Jones, S., Davis, R., Zhu, Y., Kinchin, C., Anderson, D., Hallen, R., Elliott, D., Schmidt, A., Albrecht, K., Hart, T., Butcher, M., Drennan, C., Snowden-Swan, L. 2014. Process design and economics for the conversion of algal biomass to hydrocarbons: Whole algae hydrothermal liquefaction and upgrading. U.S. Department of Energy Bioenergy Technologies Office.

Lam, M.K., Lee, K.T., 2012. Microalgae biofuels: A critical review of issues, problems and the way forward. Biotechnol Adv, 30(3), 673-690.

Lardon, L., Helias, A., Sialve, B., Stayer, J.P., Bernard, O., 2009. Life-cycle assessment of biodiesel production from microalgae. Environ Sci Technol, 43(17), 6475-6481.

Liu, X., Saydah, B., Eranki, P., Colosi, L.M., Greg Mitchell, B., Rhodes, J., Clarens, A.F., 2013. Pilot-scale data provide enhanced estimates of the life cycle energy and emissions profile of algae biofuels produced via hydrothermal liquefaction. Bioresour Technol, 148(0), 163-171.

Lundquist, T.J., Woertz, I.C., Quinn, N.W.T., Benemann, J.R. 2010. A realistic technology and engineering assessment of algae biofuel production. Energy Biosciences Institute.

Mata, T.M., Martins, A.A., Caetano, N.S., 2010. Microalgae for biodiesel production and other applications: A review. Renewable and Sustainable Energy Reviews, 14(1), 217-232. 
Menger-Krug, E., Niederste-Hollenberg, J., Hillenbrand, T., Hiessl, H., 2012. Integration of microalgae systems at municipal wastewater treatment plants: Implications for energy and emission balances. Environ Sci Technol, 46(21), 11505-11514.

Moheimani, N., 2013. Long-term outdoor growth and lipid productivity of tetraselmis suecica, Dunaliella tertiolecta and Chlorella sp (chlorophyta) in bag photobioreactors. J Appl Phycol, 25(1), 167-176.

Moody, J.W., Mcginty, C.M., Quinn, J.C., 2014. Global evaluation of biofuel potential from microalgae. Proceedings of the National Academy of Sciences.

Nagarajan, S., Chou, S.K., Cao, S., Wu, C., Zhou, Z., 2013. An updated comprehensive techno-economic analysis of algae biodiesel. Bioresour Technol, 145(0), 150-156.

Passell, H., Dhaliwal, H., Reno, M., Wu, B., Ben Amotz, A., Ivry, E., Gay, M., Czartoski, T., Laurin, L., Ayer, N., 2013. Algae biodiesel life cycle assessment using current commercial data. J Environ Manag, 129(0), 103-111.

Pate, R., Klise, G., Wu, B., 2011. Resource demand implications for US algae biofuels production scaleup. Applied Energy, 88(10), 3377-3388.

Pate, R.C., 2013. Resource requirements for the large-scale production of algal biofuels. Biofuels, 4(4), 409-435.

Pienkos, P.T., Darzins, A., 2009. The promise and challenges of microalgal-derived biofuels. Biofuels Bioproducts \& Biorefining-Biofpr, 3(4), 431-440.

Ponnusamy, S., Reddy, H.K., Muppaneni, T., Downes, C.M., Deng, S., 2014. Life cycle assessment of biodiesel production from algal bio-crude oils extracted under subcritical water conditions. Bioresour Technol, 170(0), 454-461.

Quinn, J., Catton, K., Wagner, N., Bradley, T., 2012a. Current large-scale US biofuel potential from microalgae cultivated in photobioreactors. BioEnergy Research, 5(1), 49-60. 
Quinn, J.C., Catton, K.B., Johnson, S., Thomas, H.B., 2012b. Geographical assessment of microalgae biofuels potential incorporating resource availability. BioEnergy Research, 6(2), 591-600.

Quinn, J.C., Hanif, A., Sharvelle, S., Bradley, T.H., in press. Microalgae to biofuels: Life cycle impacts of methane production of anaerobically digested lipid extracted algae. Bioresour Technol(0).

Quinn, J.C., Smith, T.G., Downes, C.M., Quinn, C., 2014. Microalgae to biofuels lifecycle assessmentmultiple pathway evaluation. Algal Research, 4, 116-122.

Quinn, J.C., Yates, T., Douglas, N., Weyer, K., Butler, J., Bradley, T.H., Lammers, P.J., 2012c. Nannochloropsis production metrics in a scalable outdoor photobioreactor for commercial applications. Bioresour Technol, 117, 164-71.

Ramachandra, T.V., Durga Madhab, M., Shilpi, S., Joshi, N.V., 2013. Algal biofuel from urban wastewater in india: Scope and challenges. Renewable and Sustainable Energy Reviews, 21(0), 767-777.

Razon, L.F., Tan, R.R., 2011. Net energy analysis of the production of biodiesel and biogas from the microalgae: Haematococcus pluvialis and Nannochloropsis. Applied Energy, 88(10), 3507-3514.

Richardson, J.W., Johnson, M.D., Outlaw, J.L., 2012. Economic comparison of open pond raceways to photo bio-reactors for profitable production of algae for transportation fuels in the southwest. Algal Research, 1(1), 93-100.

Rodolfi, L., Zittelli, G.C., Bassi, N., Padovani, G., Biondi, N., Bonini, G., Tredici, M.R., 2009. Microalgae for oil: Strain selection, induction of lipid synthesis and outdoor mass cultivation in a low-cost photobioreactor. Biotechnol Bioeng, 102(1), 100-112.

Rogers, J.N., Rosenberg, J.N., Guzman, B.J., Oh, V.H., Mimbela, L.E., Ghassemi, A., Betenbaugh, M.J., Oyler, G.A., Donohue, M.D., 2014. A critical analysis of paddlewheel-driven raceway ponds for algal biofuel production at commercial scales. Algal Research, 4(0), 76-88. 
Schenk, P.M., Thomas-Hall, S.R., Stephens, E., Marx, U.C., Mussgnug, J.H., Posten, C., Kruse, O., Hankamer, B., 2008. Second generation biofuels: High-efficiency microalgae for biodiesel production. BioEnergy Research, 1(1), 20-43.

Scott, S.A., Davey, M.P., Dennis, J.S., Horst, I., Howe, C.J., Lea-Smith, D.J., Smith, A.G., 2010. Biodiesel from algae: Challenges and prospects. Curr Opin Biotechnol, 21(3), 277-286.

Sevigné Itoiz, E., Fuentes-Grünewald, C., Gasol, C.M., Garcés, E., Alacid, E., Rossi, S., Rieradevall, J., 2012. Energy balance and environmental impact analysis of marine microalgal biomass production for biodiesel generation in a photobioreactor pilot plant. Biomass Bioenergy, 39(0), 324-335.

Shirvani, T., Yan, X., Inderwildi, O.R., Edwards, P.P., King, D.A., 2011. Life cycle energy and greenhouse gas analysis for algae-derived biodiesel. Energy \& Environmental Science, 4(10), 3773-3778.

Sills, D.L., Paramita, V., Franke, M.J., Johnson, M.C., Akabas, T.M., Greene, C.H., Tester, J.W., 2013. Quantitative uncertainty analysis of life cycle assessment for algal biofuel production. Environ Sci Technol, 47(2), 687-694.

Slade, R., Bauen, A., 2013. Micro-algae cultivation for biofuels: Cost, energy balance, environmental impacts and future prospects. Biomass Bioenergy, 53(0), 29-38.

Soh, L., Montazeri, M., Haznedaroglu, B.Z., Kelly, C., Peccia, J., Eckelman, M.J., Zimmerman, J.B., 2014. Evaluating microalgal integrated biorefinery schemes: Empirical controlled growth studies and life cycle assessment. Bioresour Technol, 151(0), 19-27.

Soratana, K., Landis, A.E., 2011. Evaluating industrial symbiosis and algae cultivation from a life cycle perspective. Bioresour Technol, 102(13), 6892-6901.

Sun, A., Davis, R., Starbuck, M., Ben-Amotz, A., Pate, R., Pienkos, P.T., 2011. Comparative cost analysis of algal oil production for biofuels. Energy, 36(8), 5169-5179.

Thilakaratne, R., Wright, M.M., Brown, R.C., 2014. A techno-economic analysis of microalgae remnant catalytic pyrolysis and upgrading to fuels. Fuel, 128(0), 104-112. 
Vasudevan, V., Stratton, R.W., Pearlson, M.N., Jersey, G.R., Beyene, A.G., Weissman, J.C., Rubino, M., Hileman, J.I., 2012. Environmental performance of algal biofuel technology options. Environ Sci Technol, 46(4), 2451-2459.

Venteris, E.R., Mcbride, R.C., Coleman, A.M., Skaggs, R.L., Wigmosta, M.S., 2014a. Siting algae cultivation facilities for biofuel production in the United States: Trade-offs between growth rate, site constructability, water availability, and infrastructure. Environ Sci Technol, 48(6), 3559-3566.

Venteris, E.R., Skaggs, R.L., Coleman, A.M., Wigmosta, M.S., 2012. An assessment of land availability and price in the coterminous United States for conversion to algal biofuel production. Biomass \& Bioenergy, 47, 483-497.

Venteris, E.R., Skaggs, R.L., Coleman, A.M., Wigmosta, M.S., 2013. A GIS cost model to assess the availability of freshwater, seawater, and saline groundwater for algal biofuel production in the United States. Environ Sci Technol, 47(9), 4840-4849.

Venteris, E.R., Skaggs, R.L., Wigmosta, M.S., Coleman, A.M., 2014b. A national-scale comparison of resource and nutrient demands for algae-based biofuel production by lipid extraction and hydrothermal liquefaction. Biomass \& Bioenergy, 64, 276-290.

Weyer, K.M., Bush, D.R., Darzins, A., Willson, B.D., 2009. Theoretical maximum algal oil production. BioEnergy Research, 3(2), 204-213.

Wigmosta, M.S., Coleman, A.M., Skaggs, R.J., Huesemann, M.H., Lane, L.J., 2011. National microalgae biofuel production potential and resource demand. Water Resources Research, 47.

Wijffels, R.H., Barbosa, M.J., 2010. An outlook on microalgal biofuels. Science, 329(5993), 796-799.

Williams, P.J.L., Laurens, L.M.L., 2010. Microalgae as biodiesel \& biomass feedstocks: Review \& analysis of the biochemistry, energetics \& economics. Energy \& Environmental Science, 3(5), 554-590. 
Woertz, I.C., Benemann, J.R., Du, N., Unnasch, S., Mendola, D., Mitchell, B.G., Lundquist, T.J., 2014. Life cycle ghg emissions from microalgal biodiesel - a ca-GREET model. Environ Sci Technol, 48(11), 6060-6068.

Xu, L.X., Brilman, D.W.F., Withag, J.a.M., Brem, G., Kersten, S., 2011. Assessment of a dry and a wet route for the production of biofuels from microalgae: Energy balance analysis. Bioresour Technol, 102(8), 5113-5122.

Yeang, K., 2008. Biofuel from algae. Architectural Design, 78(3), 118-119.

Zemke, P.E., Wood, B.D., Dye, D.J., 2010. Considerations for the maximum production rates of triacylglycerol from microalgae. Biomass Bioenergy, 34(1), 145-151. 


\title{
Figure Captions
}

Figure 1. Oil yield assumptions for growth systems found in life cycle, techno-economic, and scalability assessment. Some studies report a range for the productivity with the high end reported and the low end illustrated in grey.

Figure 2. Techno-economic results from literature color coded to growth platform and the conversion technology highlighted, SE-solvent extraction, HTL-hydrothermal liquefaction, PYpyrolysis. * denotes high value reported in the study. Some studies report current costs while others estimate future costs based on advancements in sub-processing technologies. Costs are reported in 2014 dollars based on an inflation rate of $2.4 \%$

Figure 3. Comparison of lipid productivity to biofuel cost (2014 dollars) as reported in the literature with PBR and ORP growth architectures differentiated.

\begin{abstract}
Figure 4. GHG emissions for microalgae to biofuel with a WTP system boundary as reported in the literature highlighting the growth architecture and biomass processing method, SE-solvent extraction, HTL-hydrothermal liquefaction, SN-secretion, PY-pyrolysis, SCW-supercritical water, in situ-in situ transesterification.
\end{abstract}




\section{Figures}

\section{Figure 1.}

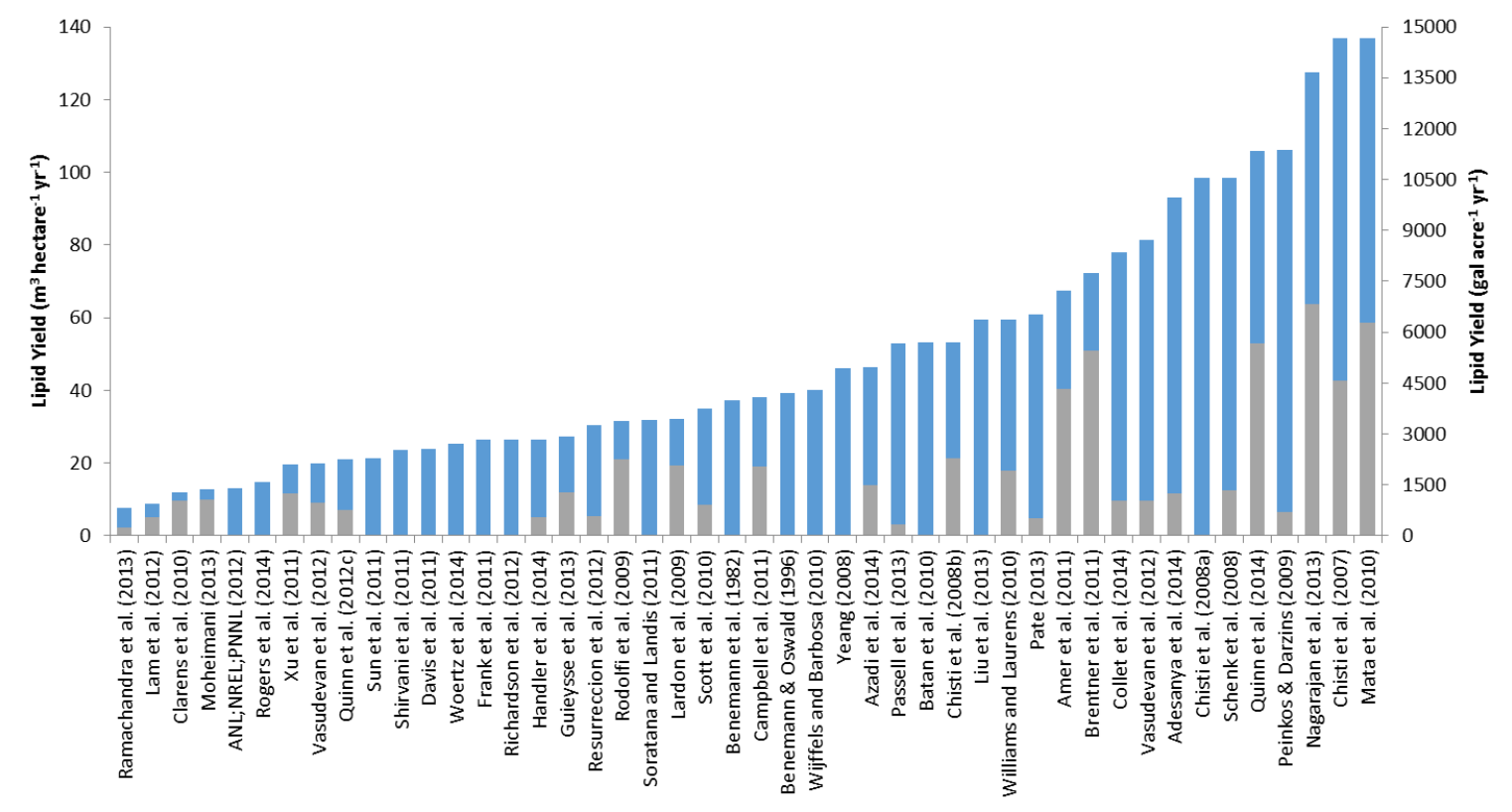

29

30

31

32

33

34

35

36

37

38

39

40

41

42

43

44

45

46

47

48

49

50

51

52

53

54

55

56

57

58

59

60

61

62 
Figure 2.

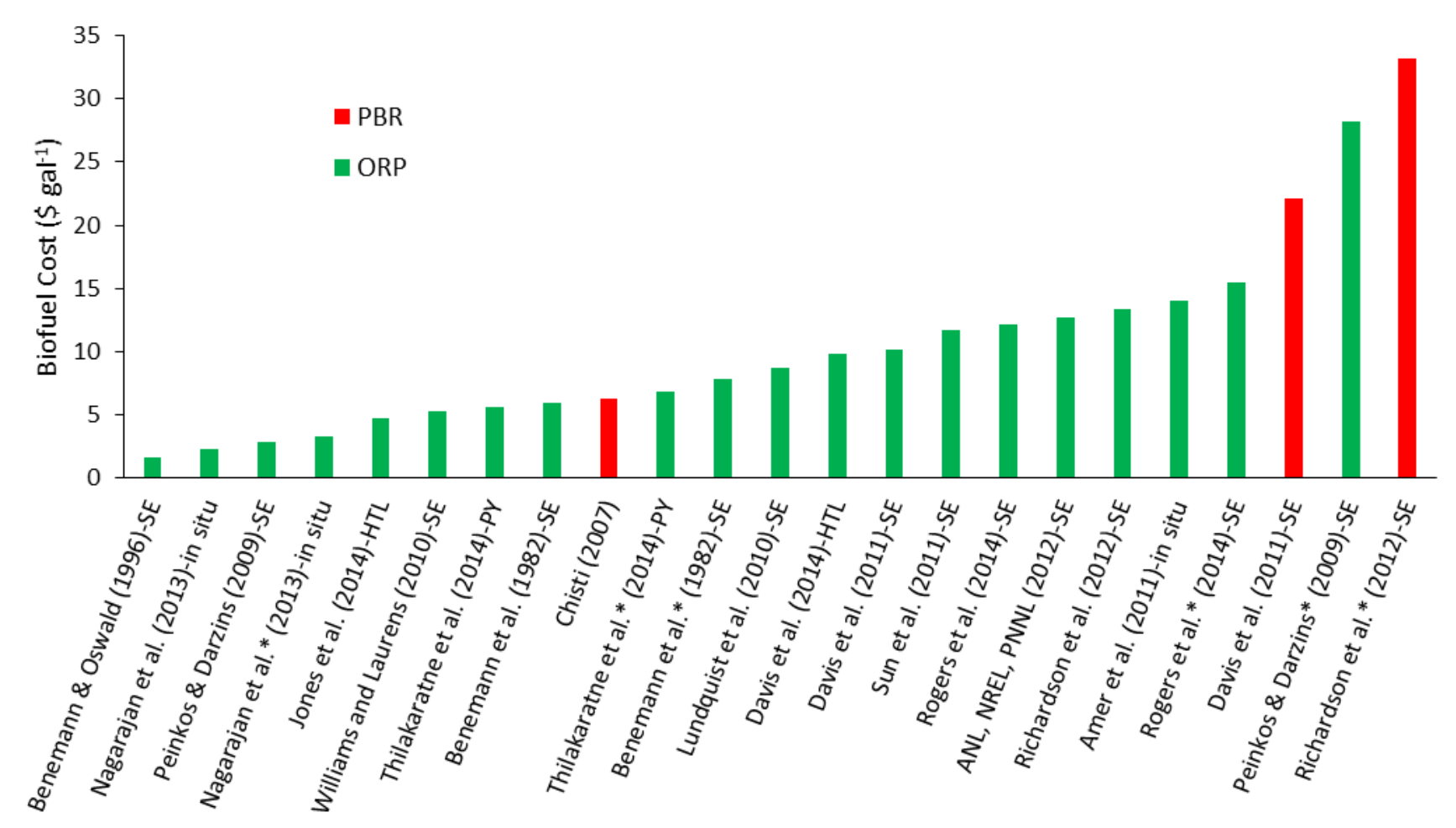


Figure 3.

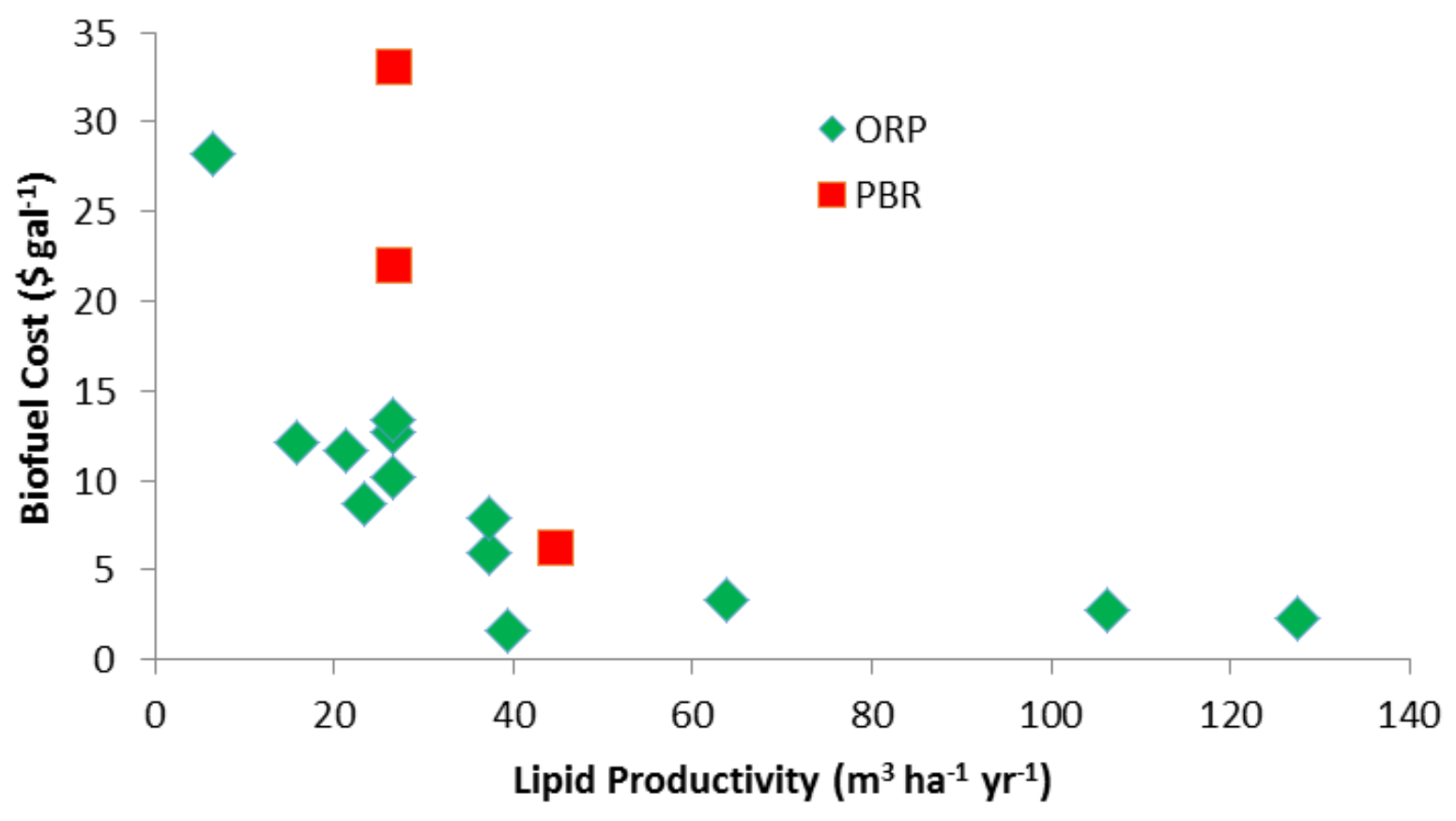

29

30

31

32

33

34

35

36

37

38

39

40

41

42

43

44

45

46

47

48

49

50

51

52

53

54

55

56

57

58

59

60

61 
Figure 4.

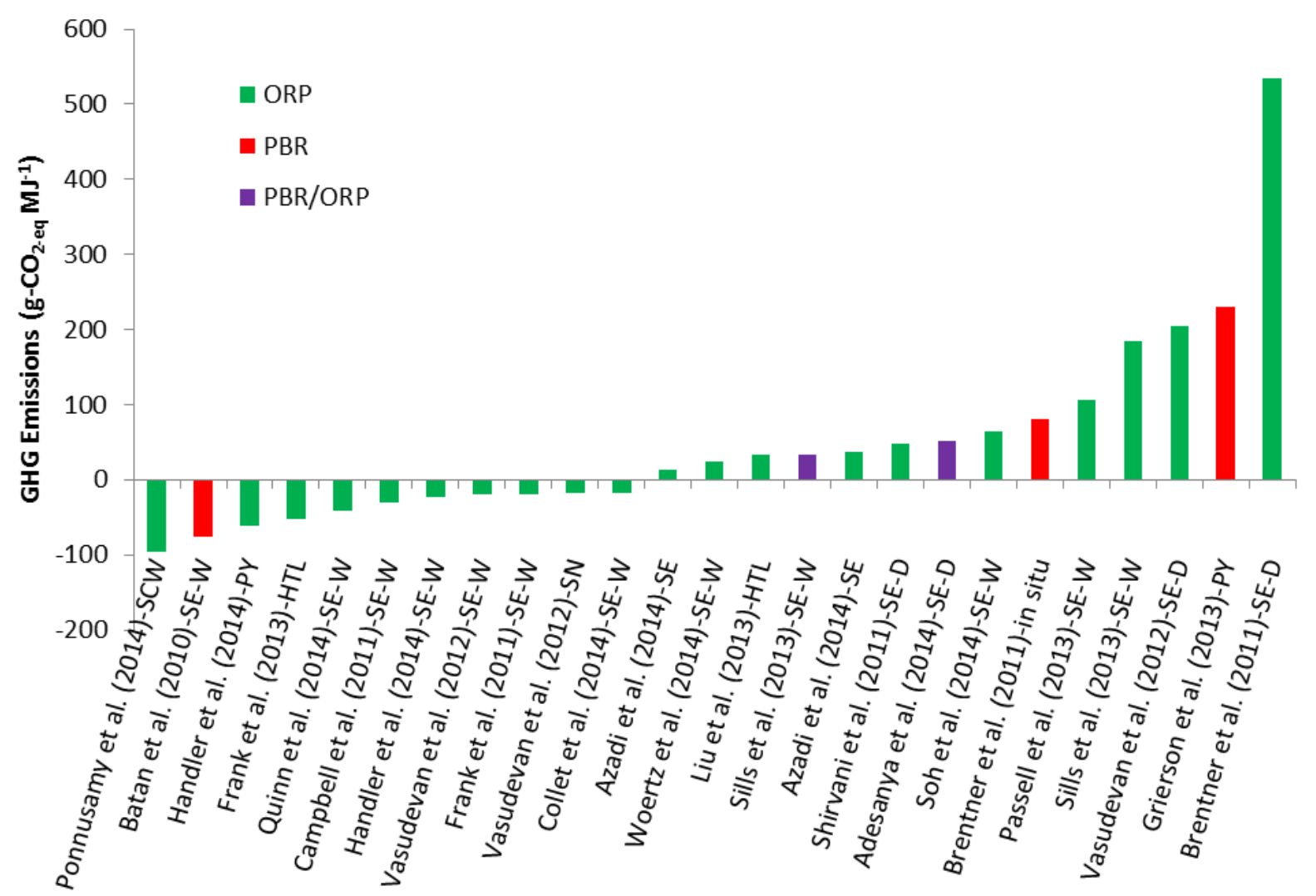

34

35

36

37

38

39

40

41

42

43

44

45

46

47

48

49

50

51

52

53

54

55

56

57

58

59

60

61 